\title{
Molecular Detection of Echinococcus granulosus Sensu Stricto in Environmental Dog Faecal Samples from the Magallanes Region, Patagonia, Chile
}

\author{
Juan Francisco Alvarez ${ }^{1, *}$, Raúl Ruiz ${ }^{2}$, Juan Ríos ${ }^{3}$ and Cristian A. Alvarez Rojas ${ }^{4, *(D)}$ \\ 1 Agricultural and Livestock Service, Punta Arenas 6212715, Chile \\ 2 Secretaría Ministerial de Salud (SEREMI), Punta Arenas 6212526, Chile; raul.ruiz@redsalud.gov.cl \\ 3 Bioquímico, Punta Arenas 6212715, Chile; rioshernandezjuan@gmail.com \\ 4 School of Veterinary Medicine, Faculties of Agriculture \& Forestry, Biological Sciences and Medicine, \\ Pontifical Catholic University of Chile, Santiago 8970117, Chile \\ * Correspondence: francisco.alvarez@sag.gob.cl (J.F.A.); c.alvarezrojas@uc.cl (C.A.A.R.)
}

check for

updates

Citation: Alvarez, J.F.; Ruiz, R.; Ríos, J.; Alvarez Rojas, C.A. Molecular Detection of Echinococcus granulosus Sensu Stricto in Environmental Dog Faecal Samples from the Magallanes Region, Patagonia, Chile. Parasitologia 2021, 1, 238-246. https://doi.org/ $10.3390 /$ parasitologia1040025

Academic Editor: Maria

Victoria Periago

Received: 15 September 2021

Accepted: 26 October 2021

Published: 4 November 2021

Publisher's Note: MDPI stays neutral with regard to jurisdictional claims in published maps and institutional affiliations.

Copyright: (c) 2021 by the authors. Licensee MDPI, Basel, Switzerland. This article is an open access article distributed under the terms and conditions of the Creative Commons Attribution (CC BY) license (https:/ / creativecommons.org/licenses/by/ $4.0 /)$.

\begin{abstract}
Echinococcus granulosus is endemic in the Magallanes region and other areas of Chile. After a successful control programme implemented between 1979 and 2004, dogs' prevalence decreased from $70 \%$ to $0.5 \%$. Since the end of the programme, no prevalence study of canine echinococcosis has been performed in this region. Dog faecal samples were collected from epidemiological units for DNA isolation and polymerase chain reaction (PCR) to detect E. granulosus. In addition, dog owners were required to answer a questionnaire for a risk factor analysis. We collected 1069 environmental dog faecal samples from 267 urban, 241 periurban, and 61 rural epidemiological units. E. granulosus was found in 11/61 (18\%) and 1/241 (0.4\%) epidemiological units from rural and periurban areas, respectively. The Ultima Esperanza province showed the highest prevalence with eight out of 16 units with faeces positive to E. granulosus showing a main spatial cluster of canine echinococcosis. None of the risk factors investigated showed a statistical significance with positive units. This study shows the active transmission of the parasite in the Magallanes region, especially in the Ultima Esperanza province, with a possible re-emergence of the parasite. Further studies focusing on the incidence in humans are required together with the reestablishment of the compulsory deworming of dogs.
\end{abstract}

Keywords: Echinococcus granulosus; cystic echinococcosis; Chile; Magallanes; dog; canine echinococcosis; prevalence; PCR; spatial clustering; control programme

\section{Introduction}

Cystic echinococcosis (CE), caused by the parasite Echinococcus granulosus, remains a significant health problem in Chile [1,2]. The human incidence based on hospital records fluctuated between 4.68 and $5 / 10^{5}$ population in 2009-2014 in Chile [1]. However, it is known that under-reporting of CE occurs in Chile [3], as in other endemic countries [4]; therefore, the actual incidence of $\mathrm{CE}$ is expected to be higher. As a result, CE produces losses estimated at USD 3.13 M per year in Chile [3]. Furthermore, the infection with E. granulosus in livestock represents the second most important cause of condemnation of viscera at official abattoirs after Fasciola hepatica [5], causing losses estimated between USD 7 and 11.2 M per year [6].

The Chilean territory comprises $4270 \mathrm{~km}$ (north-south) with several biogeographic areas divided into sixteen administrative regions. The Magallanes region (also known as XII region in previous reviews concerning the control of E. granulosus $[7,8])$ is the southernmost, the largest $\left(132,291 \mathrm{~km}^{2}\right)$ and the second least populated region in the country, with 165,593 inhabitants. There are 2,205,477 sheep heads in the region, which is equivalent to $56 \%$ of the total ovine population in Chile [9]. E. granulosus is highly endemic in the Magallanes region; in 1979, the prevalence for E. granulosus was around 60\% 
and $70 \%$ in sheep and dogs, respectively, while the human incidence for CE was $40 / 10^{5}$ inhabitants. Consequently, a control programme was established in 1979. By 1993, the prevalence was reduced to $4.6 \%$ in sheep and $5.4 \%$ in dogs, while the incidence in humans decreased to $15.6 / 10^{5}$ inhabitants [10]. The programme continued until 2004 without achieving the consolidation stage, which could have resulted in eradicating transmission. Nevertheless, the programme's success has led to it being deemed as one of the most effective initiatives to control CE in a continental setting [7]. The lowest infection in dogs reported when the programme was in action was $0.5 \%$ in 1994 . However, by 2002, a study based on arecoline purgation reported a prevalence for canine echinococcosis of $1.8 \%$ in the region [11], suggesting a risk of re-emergence. Subsequently, infection in sheep from Magallanes in 2015-2016 reached 2.9\% [12]. Therefore, there is a need for further surveillance of the level of infection in dogs in the region; such data will allow for an understanding of the current status of transmission of the parasite and form the basis of future studies investigating infection in livestock and humans. In this study, we aim to estimate the prevalence of E. granulosus in dogs from the Magallanes region using PCR from faecal samples collected in the environment, perform statistical, epidemiological and spatial analyses of the distribution of the parasite, and include a questionnaire to identify possible risk factors for $\mathrm{CE}$.

\section{Results}

In total, 1069 environmental dog faecal samples were collected from 569 epidemiological units, including the extra $5 \%$ mentioned in the materials and methods section. From the total number of epidemiological units, 267 were located in urban areas, 241 in periurban areas, and 61 in rural areas. In total, 11/61 (18\%) and 1/241 (0.4\%) epidemiological units from the rural and periurban areas, respectively, were found to be positive to E. granulosus s.s. The PCR for E. granulosus s.s. was negative for all samples from the 267 epidemiological units located in the urban area (Table 1).

Table 1. Total number of epidemiological units included in the study from rural, urban and periurban areas in the Magallanes region and number of units where E. granulosus s.s. was found in environmental dog faecal samples (based on PCR and sequencing).

\begin{tabular}{cccccc}
\hline Area & $\begin{array}{c}\text { \# Epidemiological } \\
\text { Units }\end{array}$ & $\begin{array}{c}\text { \# of Environmental } \\
\text { Dog Faecal Samples } \\
\text { Collected }\end{array}$ & $\begin{array}{c}\text { \# of Positive Units for } \\
\text { E. granulosus s.s. }\end{array}$ & Prevalence (\%) & $\boldsymbol{p}$-Value \\
\hline Rural & 61 & 393 & 11 & 18 & $p<0.0001$ \\
Periurban & 241 & 369 & 1 & 0.4 & 0 \\
Urban & 267 & 307 & 0 & 2.1 \\
\hline Total & 569 & 1069 & 12 & \\
\hline
\end{tabular}

Odd Ratio $=111.32 ; 95 \%$ CI $=14.08$ to 880.14 .

Table 2 shows the detailed results from the environmental dog faecal samples investigated in the 61 epidemiological units from the rural area, in each of the region's four provinces. The Ultima Esperanza province showed a prevalence of 50\% (8/16 epidemiological units), while in Tierra del Fuego the prevalence was 11.54\% (3/26 epidemiological units). The percentage of infected dogs within the 12 epidemiological units considered positive in this study varied between 5 and $100 \%$ (Table 3). 
Table 2. Prevalence of E. granulosus s.s. in epidemiological units from the rural area sampled in this study according to each province of the Magallanes region in Chile.

\begin{tabular}{cccccc}
\hline Province & $\begin{array}{c}\text { \# Epidemiological } \\
\text { Units }\end{array}$ & $\begin{array}{c}\text { \# of Positive Units for } \\
\text { E. granulosus s.s. }\end{array}$ & Prevalence (\%) & $p$ Value & Sheep Population [9] \\
\hline Ultima Esperanza & 16 & 8 & 50 & $p<0.0001$ & 213,746 \\
Tierra del Fuego & 26 & 3 & 11.54 & $1,046,409$ \\
Magallanes & 16 & 0 & 0 & 944,919 \\
Antártica Chilena & 3 & 0 & 0 & 196 \\
\hline Total & 61 & 11 & 18.03 & $2,205,270$ \\
\hline
\end{tabular}

Odd Ratio $=14.0 ; 95 \%$ CI $=3.04$ to 64.48 .

Table 3. Province and code of the epidemiological units (11 from rural and one from periurban areas) where at least one environmental dog faecal sample was found to be positive for E. granulosus s.s.

\begin{tabular}{ccc}
\hline Province & Epidemiological Unit Code & $\begin{array}{c}\text { \# Positive Samples for E. granulosus s.s./Total } \\
\text { Dog Faecal Samples }\end{array}$ \\
\hline Magallanes (periurban) & HOUSE1532 & $1 / 1(100 \%)$ \\
\hline \multirow{2}{*}{ Tierra del Fuego (rural) } & TF59A63 & $1 / 5(20 \%)$ \\
& TF26A30 & $1 / 5(20 \%)$ \\
& TF157A176 & $1 / 20(5 \%)$ \\
\hline & UE51A55 & $4 / 5(80 \%)$ \\
Ultima Esperanza (rural) & UE24A27 & $3 / 4(75 \%)$ \\
& UE20A23 & $2 / 4(50 \%)$ \\
& UE71A82 & $6 / 12(50 \%)$ \\
& UE45A47 & $1 / 3(33.3 \%)$ \\
& UE28A34 & $2 / 7(28.5 \%)$ \\
& UE11A19 & $2 / 9(22.2 \%)$ \\
\hline
\end{tabular}

The PCR for E. granulosus s.s. was negative in all 334 environmental faecal samples from dogs collected in public squares from Punta Arenas and Puerto Natales.

The questionnaire (Supplementary Table S1) was answered by 521 people. After an univariate analysis of responses, none of the risk factors investigated showed statistical significance. The "average of dogs per unit" variable showed some evidence of association ( $p=0.0295)$; however, this variable did not remain significant in the model for the logistic regression analysis.

General clustering was found in the spatial analysis in the epidemiological units positive to E. granulosus, considered as cases $(p<0.001)$. The main cluster of canine echinococcosis (using the Kulldorff spatial scan statistic) was found in the Ultima Esperanza province $(p<0.001)$. The cluster centre point was located in the epidemiological unit UE20A23 $\left(51^{\circ} 33^{\prime} \mathrm{S}-72^{\circ} 40^{\prime} \mathrm{O}\right)$, with a radius of $85.9 \mathrm{~km}$ and a total area comprising $23,181 \mathrm{~km}^{2}$ (Figure 1). 


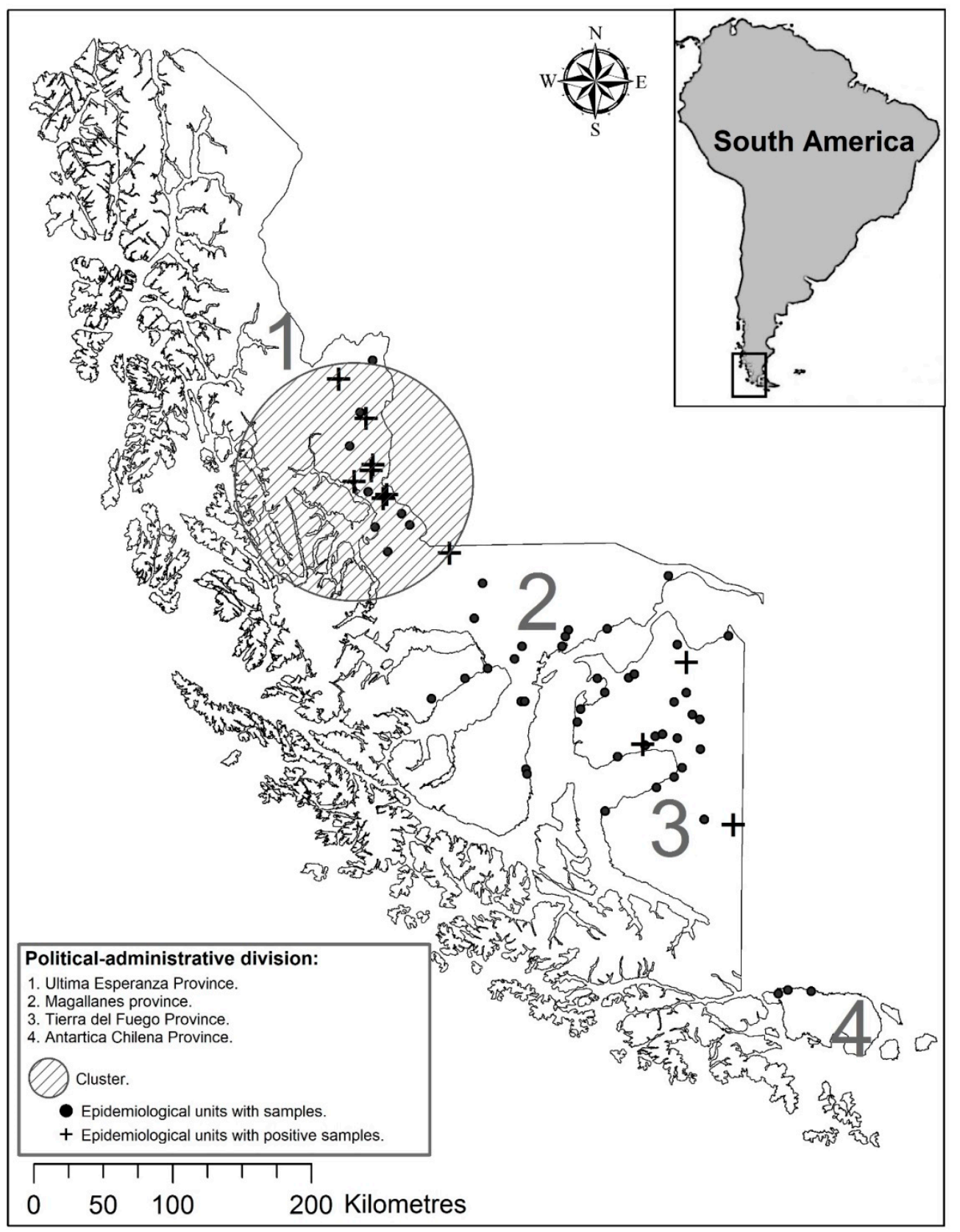

Figure 1. Dots showing the distribution of the epidemiological units sampled in rural areas from the Magallanes Region, Chile. The cluster of positive samples located in the Ultima Esperanza province is also shown.

\section{Discussion}

The present study reports, for the first time since the end of the control programme in 2004, the prevalence of E. granulosus using PCR in environmental dog faecal samples collected in all provinces of the Magallanes region. The deworming of dogs with praziquantel used to be compulsory when the control programme was in action; since 2004, dog owners have treated their animals voluntarily.

The dog prevalence for E. granulosus s.s. reported in this study was higher in rural areas, consistent with the natural history of the parasite's cycle [13]. We also investigated environmental dog faecal samples from urban and periurban areas, since the parasite can be transmitted through dogs from urban areas that predate on sheep in the nearby rural areas or through the home slaughter of sheep in periurban areas. In this case, we found a single epidemiological unit positive to E. granulosus s.s. from the periurban 
area, showing a gradient of a higher prevalence from the rural area to the absence of positives in the urban area. The prevalence of E. granulosus s.s. in dogs in the present study $(18 \%)$ was ten times higher than the one reported in the last survey performed in the Magallanes region in 2002 (1.8\%) [11]. However, it is important to consider that Alvarez et al. [11] determined the level of infection with arecoline purgation of individual dogs and not based on epidemiological units. It is well known that purgation with arecoline has a low sensitivity and a low negative predictive value [14], suggesting that the actual prevalence was likely to have been underestimated. The present investigation considered epidemiological units (farm or house) rather than individual dogs; an epidemiological unit was deemed to be positive if at least one environmental dog faecal sample collected (from that unit) resulted in being positive in the PCR and sequencing for E. granulosus s.s. Testing epidemiological units instead of single faecal samples is recommended [15] because it is assumed that all risk factors that are the subject of control are present in a single unit. If positive samples are found in a unit, then the treatment should focus on all dogs present in that unit independently of whether they are or are not infected at the time of sampling. Furthermore, the PCR-based diagnostic method, as used in this study, offers a higher sensitivity than other techniques. However, the capacity for copro-PCR to detect infected animals is dependent on the worm burden and is less sensitive in the prepatent period compared with copro-ELISA [16]. We performed two PCRs; in the first one we used primers which were able to amplify all taeniids. The second PCR (specific for E. granulosus s.s.) was performed with the DNA from samples which were positive in the first PCR. These two PCRs are not suitable for a large number of samples due to their high cost. We did not include controls to check for the presence of PCR inhibitors, and this should be taken into account for similar studies in the future.

When we analyse the prevalence according to a political-administrative division (province), the Ultima Esperanza province remains the one with the highest prevalence, followed by the Tierra del Fuego and the Magallanes provinces, as previously reported in 1982 [11]. The reasons for the differences in prevalence according to the province found in this study are unknown; however, such data could allow for the prediction of hotspots for $\mathrm{CE}$ in humans. Interestingly, in a study of the transmission of the related parasite Echinococcus multilocularis in China, it was observed that cases of alveolar echinococcosis were not directly correlated with small mammal reservoir host species richness but were rather spatially correlated with landscape features and climate [17]. In the Magallanes region, there are different climates, including cold steppe and semi-arid, with differences in humidity. However, it is unknown if the climatic differences amongst provinces favour the transmission of E. granulosus (for example: the survival of eggs in the environment), which could explain the higher prevalence found in Ultima Esperanza. On the other hand, eggs of Echinococcus spp. can remain infective for extended periods; for example, E. multilocularis eggs can survive up to 240 days under German autumn/winter conditions and 78 days in summer [18]. At the same time, eggs of E. granulosus remained viable for up to 41 months in the environment of Argentinian Patagonia [19] and for only four winter months in New Zealand [20]. The high variability in the number of days during which eggs can survive in the environments reported in different studies can be attributed to environmental conditions but also the quality of the eggs used and the experimental setting. Ultima Esperanza province has only 216,000 sheep compared with the 2,205,270 sheep in the region. In the Tierra del Fuego province, we found 3/26 (11.54\%) epidemiological units with faeces infected with E. granulosus. A previous study described a cluster for $\mathrm{CE}$ in sheep in Ultima Esperanza based on slaughterhouse official records between July 2016 and June 2017 [12], confirming that special situations, which need to be investigated, favour the transmission of the parasite in Ultima Esperanza. Cluster analysis also located a focus of transmission in Ultima Esperanza in the present study. Describing disease clustering and disease clusters supports decision-making and can also be used to undertake a risk factor analysis [21]. Likewise, it is suggested that a control programme should begin to focus on farms with a high prevalence and identified diseases cluster [22]. 
Tierra del Fuego is an island shared between Chile and Argentina. Interestingly, on the Argentinian side of the island, a prevalence of $6 \%$ in farms was reported using coproELISA in 2018 [23]. Considering the cross-reactivity of copro-ELISA with other taeniids (i.e., T. hydatigena) [16], it is likely that the actual level of infection with E. granulosus could have been overestimated [23]. The official control activities against E. granulosus on Argentine territory, including the mandatory and periodic deworming of dogs, have not been interrupted since 1982, in contrast with the situation in Chile, in which deworming is voluntary and is the responsibility of dog owners.

In the present study, we found no statistical association between the risk factors assessed by the questionnaire answered by dog owners on farms and the result of the laboratory analysis. This issue could have been caused by the study design and related to the statistical power (e.g., a low number of samples for obtaining statistical associations or determining differences); this situation should be considered in the design of future similar studies. Nevertheless, risk factors associated with the transmission of E. granulosus are known and have been widely studied. Furthermore, using two spatial analysis tests, we found clusters of canine echinococcosis.

Several control initiatives have been implemented in different regions in Chile (not Magallanes) in the last ten years [2]. Unfortunately, they have been funded for short periods of two or four years maximum, which are not enough to produce a significant and long-lasting decrease in the transmission of E. granulosus. On the contrary, the official control programme in the Magallanes region lasted for 25 years between 1979 and 2004. The measures implemented included the mandatory treatment of dogs with praziquantel by staff from the Servicio Agrícola y Ganadero (Livestock and Agricultural Service, SAG), strict control of the canine population, construction of elimination ditches for livestock viscera, banning of feeding dogs with viscera, and health education for dog owners, schoolchildren and the general public [10]. The transition to a consolidation phase occurred in 2004 when dogs were treated voluntarily by their owners. However, the eradication of transmission was not achieved. Based on the data from this study, we can conclude that the transmission of E. granulosus remains active in the Magallanes region, especially in the Ultima Esperanza province. This situation suggests a re-emergence of the infection after the end of the control programme, which requires the attention of the authorities. We recommend focusing on the areas showing clusters of E. granulosus, to begin with a periodic treatment of dogs with praziquantel.

\section{Materials and Methods}

\subsection{Study Area and Sampling Strategy}

The sampling was carried out between August 2017 and February 2018 in all four provinces of the Magallanes region, from north to south: Última Esperanza, Magallanes, Tierra del Fuego, and Antártica Chilena. Environmental dog faecal samples were taken from rural, periurban and urban areas. The rural area included sheep farms from all four provinces; each farm had an official identification (RUP: rol unico predial/unique farm number) and was georeferenced. The periurban area comprised $200 \mathrm{~m}$ inside the urban limit of the cities Punta Arenas and Puerto Natales, including "country houses" located in properties with an area $<5000 \mathrm{~m}^{2}$ directly connected with the urban boundary. The urban area included houses in the Porvenir city (Tierra del Fuego province), and the towns Cerro Sombrero (Tierra del Fuego), Puerto Williams (located on an island in Antartica Chilena) and Puerto Edén (located on an island in Ultima Esperanza).

Each farm (from the rural area) or house (from the urban and periurban area) having at least one dog was considered an 'epidemiological unit'. The sample size (epidemiological units) was estimated based on the total number of dogs in the rural area (estimated to be 12,600 dogs) considering the historical data on the number of dogs per farm, a prevalence of $4.7 \%$ in dogs (from unpublished data from the Porvenir city), a 95\% confidence level and a 3\% error. Once the number of epidemiological units was estimated, an additional 5\% was added to cover the likely loss of samples. The number of environmental dog faecal samples 
collected at each epidemiological unit was equal to the total number of dogs present in each unit; therefore, it was possible that, in some cases, faeces belonged to some but not all dogs.

\subsection{Faecal Samples Collection and Detection of E. granulosus DNA}

Five to $10 \mathrm{~g}$ of environmental fresh dog faecal samples were collected in a plastic container from the ground. If no fresh faeces were available, semi-dried faeces were collected. Faecal samples were labelled and kept in a cool box in the field and subsequently transported to the laboratory and stored at $-80^{\circ} \mathrm{C}$ for five days to inactivate $E$. granulosus eggs if present. DNA was isolated from total faeces with the QIAamp DNA mini kit following the manufacturer's instructions. Initially, all samples were subjected to PCR to amplify a section of the cox1 gene of different taeniids, according to Bowles et al. [24]. DNA from positive samples was used in a second PCR targeting the 12sRNA using specific primers for E. granulosus s.s. [25]. An epidemiological unit was considered positive when at least one environmental dog faecal sample was found positive in the PCR for the amplification and sequencing of the $12 \mathrm{~S}$ rRNA gene.

\subsection{Questionnaire}

The dog owner(s) from each epidemiological unit in the rural area answered a set of questions aiming to identify risk factors for CE (supplementary information in Supplementary Table S1); briefly, the question aimed to find out: the political-administrative location, the data of dog owners, the characteristics of the dogs, dog husbandry and veterinary treatments, the presence of livestock and wild animals, and knowledge about cystic echinococcosis.

\subsection{Statistical Analysis}

We used univariate nonparametric methods (Fisher's exact test and $\chi^{2}$ ) with an odds ratio and confidence intervals at $95 \%$. For the quantitative variables, we used the MannWhitney test; subsequently, the variables with an association $(p<0.3)$ were used for a logistic regression analysis (step by step) with an entry $p$-value lower than 0.1 , using the software MedCalc ${ }^{\circledR}$ v13.3.3 (https:/ / www.medcalc.org/, accessed on 19 January 2021).

For the spatial analysis, we associate the database with the cartographic data from the rural area with farms tested using the software ArcGIS 9 (https: / desktop.arcgis.com/ en/arcmap/, accessed on 24 February 2021). Two spatial analysis tests were performed: Cuzick\&Edwards and the Kulldorff spatial scan statistic. The Cuzick\&Edwards test uses geospatial data to compare the case(s) and control(s) locations. The case was defined as an epidemiological unit with positive PCR and sequencing showing infection with $E$. granulosus in dog faeces. At the same time, a negative PCR result in an epidemiological unit was considered as a control. Cases were coded with the number 1 and controls with 0 , the Tk value being the number of cases closer to each case [26]. We tested values between 1 and 10 nearest-neighbour levels. Finally, the significance was calculated with the z-value, and we used the Simes correction method for each nearest-neighbour level using the software ClusterSeer (https:/ / www.biomedware.com/software/clusterseer/, accessed on 24 February 2021). The Kulldorff spatial scan statistic is defined as a "circular geographic window" that moves over the area of interest; it is centred in turn around each of several possible clusters, with the window radius being allowed to vary between zero and some upper limit [27]. In this study, we considered 1\% of the population to be at risk. Each newly created window includes neighbouring areas and is classified as a cluster comparing the number of cases inside each window with the expected number of cases. We assumed the existence of the Bernoulli distribution, which defines the number of cases (number of positive faecal samples) and controls (number of faecal samples when subtracting the number of positive faecal samples). The analysis was performed to define clusters with more E. granulosus cases than expected, which was equivalent to a one-tail statistical test. A probability was calculated for each window, and its $p$-value was obtained by the Monte 
Carlo method with 999 simulations and a 0.1\% significance level using the software SatScan (https:/ / www.satscan.org/, accessed on 3 March 2021).

Supplementary Materials: The following are available online at https:/ / www.mdpi.com/article/10 .3390/ parasitologia1040025/s1, Table S1: Questionnaire to be answered by each dog owner.

Author Contributions: Conceptualization, J.F.A., R.R.; methodology, J.F.A., R.R., C.A.A.R.; software, J.F.A., J.R.; validation, J.F.A., C.A.A.R.; investigation, J.F.A., C.A.A.R.; data curation, J.F.A., R.R., J.R.; writing-original draft preparation, J.F.A., C.A.A.R..; writing-review and editing, J.F.A., C.A.A.R.; visualization, J.F.A.; supervision, J.F.A., C.A.A.R.; project administration, J.F.A., R.R.; funding acquisition, J.F.A., R.R. All authors have read and agreed to the published version of the manuscript.

Funding: This research was funded by the Gobierno Regional Magallanes y Antártica Chilena, Servicio Agrícola y Ganadero and Secretaría Regional Ministerial de Salud de Magallanes, Project \#BIP-30460835-0.

Institutional Review Board Statement: Not applicable.

Informed Consent Statement: Not applicable.

Data Availability Statement: Not applicable.

Acknowledgments: A special thanks to the technicians and veterinarians of SAG and SEREMI de Salud of Magallanes region, who collaborated with the sampling.

Conflicts of Interest: The authors declare no conflict of interest.

\section{References}

1. Navarro, A.M.; Pavletic, C.; Gavidia, C.; Ferreira, C.; Caldas, E.; Guarnera, E.; Larrieu, E.; Sayes, J.; Vizcaychipi, K.; Grande, L.D.; et al. Equinococosis: Informe Epidemiológico en la Región de América del Sur 2009-2014; PANAFTOSA-PAHO/WHO: Washington, DC, USA, 2015.

2. Alvarez Rojas, C.A.; Fredes, F.; Torres, M.; Acosta-Jamett, G.; Alvarez, J.F.; Pavletic, C.; Paredes, R.; Cortés, S. First meeting “Cystic echinococcosis in Chile, update in alternatives for control and diagnostics in animals and humans". Parasites Vectors $2016,9,502$. [CrossRef] [PubMed]

3. Venegas, J.; Espinoza, S.; Sánchez, G. Estimación del impacto económico de la equinococosis quística en Chile y análisis de las posibles causas que han dificultado su erradicación. Rev. Méd. Chile 2014, 142, 1023-1033. [CrossRef] [PubMed]

4. Casulli, A. Recognising the substantial burden of neglected pandemics cystic and alveolar echinococcosis. Lancet Glob. Health 2020, 8, e470-e471. [CrossRef]

5. SAG. Informe Beneficio y Hallazgos Patológicos en Mataderos Nacionales 2017; Ganadero, S.A.Y., Ed.; Ministerio de Agricultura: Santiago, Chile, 2018.

6. FAO. Estimación del Impacto Económico de la Equinococosis Quística en el Cono Sur (Argentina, Brasil, Chile y Uruguay; Oficina Regional para América Latina y el Caribe); FAO/RLC: Santiago, Chile, 2007.

7. Craig, P.S.; Hegglin, D.; Lightowlers, M.W.; Torgerson, P.R.; Wang, Q. Echinococcosis: Control and prevention. In Advances in Parasitology; Thompson, R.C.A., Deplazes, P., Lymbery, A.J., Eds.; Academic Press: Cambridge, MA, USA, 2017; Volume 96, pp. 55-158.

8. Craig, P.S.; Larrieu, E. Control of cystic echinococcosis/hydatidosis: 1863-2002. Adv. Parasitol. 2006, 61, 443-508. [PubMed]

9. INE. Censo Agropecuario Nacional. Available online: http://www.censoagropecuario.cl/files/Tabulados_Censo_Agropecuario_ 2006_2007_Definitivo/12.xls (accessed on 7 March 2021).

10. Vidal, M.; Bonilla, C.; Jeria, E.; Gonzalez, C.G. The hydatidosis control program: The Chilean model. In Proceedings of the Scientific Working Group on the Advances in the Prevention, Control and Treatment of Hydatidosis, Montevideo, Uruguay, 26-28 October 1994.

11. Alvarez, J.F.; Tamayo, R.; Ernst, S. Estimación de la prevalencia de equinococosis canina en la XII Región, Chile, 2002. Parasitol. Latinoam. 2005, 60, 74-77. [CrossRef]

12. Alvarez, J.F. Decomisos en plantas faenadoras de ovinos temporada 2015-2016, Región de Magallanes, Patagonia, Chile. Rev. Argent. Prod. Anim. 2017, 37, 142.

13. Romig, T.; Deplazes, P.; Jenkins, D.; Giraudoux, P.; Massolo, A.; Craig, P.S.; Wassermann, M.; Takahashi, K.; de la Rue, M. Chapter Five-Ecology and life cycle patterns of Echinococcus species. In Advances in Parasitology; Thompson, R.C.A., Deplazes, P., Lymbery, A.J., Eds.; Academic Press: Cambridge, MA, USA, 2017; Volume 95, pp. 213-314.

14. Schantz, P. Sources and uses of survaillance data for cystic echinococcosis. In Compendium on Echinococcosis in Africa and in Middle Eastern Countries with Special Reference to Morocco; Andersen, F.L., Ouhelli, H., Kachani, M., Eds.; Brigham Young University Print Services: Provo, UT, USA, 1997; pp. 72-84. 
15. Larrieu, E.; Gavidia, C.M.; Lightowlers, M.W. Control of cystic echinococcosis: Background and prospects. Zoonoses Public Health 2019, 66, 889-899. [CrossRef] [PubMed]

16. Craig, P.; Mastin, A.; van Kesteren, F.; Boufana, B. Echinococcus granulosus: Epidemiology and state-of-the-art of diagnostics in animals. Vet. Parasitol. 2015, 213, 132-148. [CrossRef] [PubMed]

17. Giraudoux, P.; Raoul, F.; Pleydell, D.; Li, T.; Han, X.; Qiu, J.; Xie, Y.; Wang, H.; Ito, A.; Craig, P.S. Drivers of Echinococcus multilocularis transmission in China: Small mammal diversity, landscape or climate? PLoS Negl. Trop. Dis. 2013, 7, e2045. [CrossRef] [PubMed]

18. Veit, P.; Bilger, B.; Schad, V.; Schäfer, J.; Frank, W.; Lucius, R. Influence of environmental factors on the infectivity of Echinococcus multilocularis eggs. Parasitology 2009, 110, 79-86. [CrossRef] [PubMed]

19. Thevenet, P.S.; Jensen, O.; Drut, R.; Cerrone, G.E.; Grenóvero, M.S.; Alvarez, H.M.; Targovnik, H.M.; Basualdo, J.A. Viability and infectiousness of eggs of Echinococcus granulosus aged under natural conditions of inferior arid climate. Vet. Parasitol. 2005, 133, 71-77. [CrossRef] [PubMed]

20. Sweatman, G.K.; Williams, R.J. Survival of Echinococcus granulosus and Taenia hydatigena eggs in two extreme climatic regions of New Zealand. Res. Vet. Sci. 1963, 4, 199-218. [CrossRef]

21. Ward, M.P. Spatio-temporal analysis of infectious disease outbreaks in veterinary medicine: Clusters, hotspots and foci. Vet. Ital. 2007, 43, 559-570. [PubMed]

22. Hombo, H.; Oyarzo, M.; Álvarez, C.; Cuadros, N.; Hernández, F.; Ward, M.P.; Acosta-Jamett, G. Spatial epidemiology of cystic echinococcosis in livestock from a hyper-endemic region in southern Chile. Vet. Parasitol. 2020, 287, 109258. [CrossRef] [PubMed]

23. Petrina, J.P.; Rodriguez Eugui, J.I.; Disalvo, V.N. Actualización en la lucha contra hidatidosis en tierra del fuego. In XXXIII Jornadas Nacionales de Hidatidosis, Catamarca; Asociación Parasitológica Argentina: La Plata, Argentina, 2018.

24. Bowles, J.; Blair, D.; McManus, D.P. Genetic variants within the genus Echinococcus identified by mitochondrial DNA sequencing. Mol. Biochem. Parasitol. 1992, 54, 165-173. [CrossRef]

25. Štefanić, S.; Shaikenov, B.S.; Deplazes, P.; Dinkel, A.; Torgerson, P.R.; Mathis, A. Polymerase chain reaction for detection of patent infections of Echinococcus granulosus ("sheep strain") in naturally infected dogs. Parasitol. Res. 2004, 92, 347-351. [CrossRef] [PubMed]

26. Cuzick, J.; Edwards, R. Spatial clustering for inhomogeneous populations. J. R. Stat. Society. Ser. B Methodol. 1990, 52, 73-104. [CrossRef]

27. Kulldorff, M.; Nagarwalla, N. Spatial disease clusters: Detection and inference. Stat. Med. 1995, 14, 799-810. [CrossRef] 